\title{
Desigualdade, conectividade e direito à educação em tempos de pandemia
}

- Inequality, connectivity, and the right to education in
times of pandemic

Susana Beatriz Sacavino ${ }^{1}$

Vera Maria Candau ${ }^{2}$

Resumo: $O$ artigo parte da constatação de que a pandemia do COVID-19 escancarou as enormes desigualdades presentes na sociedade brasileira e as inter-relações entre elas. Entende os Direitos Humanos como processos históricos, sempre em construção, na busca permanente de condições de vida justas e dignas para todos. Nesse contexto, situam as questões relativas ao direito à educação. Tem presente os esforços e lutas de diversos grupos sociais, particularmente, a partir da Constituição Brasileira de 1988, para a afirmação desse direito. Assinala que houve conquistas relevantes, mas que ainda temos muito que caminhar para que todos possam ter uma educação de qualidade. Tendo presente o contexto atual e a implantação do "ensino remoto emergencial", por parte de muitos sistemas municipais e estaduais de educação, afirma que emerge com força a necessidade de garantir o direito de todos ao acesso às tecnologias de comunicação e informação, especialmente as mídias digitais, como um componente fundamental do direito à educação. No entanto, é importante não se ter uma visão meramente instrumental dessa questão, muitas vezes, reduzida à utilização de pacotes oferecidos por diver-

1 Doutorado em Educação pela Pontifícia Universidade Católica do Rio de Janeiro. Coordenadora Executiva da organização não governamental (ONG) Novamerica. Membro do Grupo de Pesquisas sobre Cotidiano, Educação e Culturas (GECEC) do Departamento de Educação da PUC-Rio. sbsacavino@novamerica.org.br - ORCID: https:// orcid.org/0000-0002-2624-4033

2 Doutorado em Educação pela Universidad Complutense de Madrid (Espanha). Professora emérita do Departamento de Educação da PUC-Rio. Coordenadora do grupo de Estudos sobre Cotidiano, Educação e Culturas (GECEC). Pesquisadora Sênior do CNPq. vmfc@puc-rio.br - ORCID: https://orcid.org/0000-0001-6987-6885 
sas organizações numa perspectiva mercadológica. É fundamental levar em consideração que a cultura digital está cada vez mais presente em diferentes âmbitos da vida social e afeta diversas dimensões de nossas vidas, individual e coletivamente, e nos desafia a entender, como educadores, formas de aprendizagem múltiplas, suas possibilidades e limites. $O$ texto defende a posição de que, além da universalização do acesso, é fundamental promover processos de letramento digital de forma contínua, processual e sistemática, tanto orientada aos alunos e alunas, como aos professores e professoras, que permitam afirmar o direito à conectividade numa perspectiva educacional reflexiva, crítica e criativa.

Palavras-chave: Direito à educação. Direito à conectividade. Cultura digital. Letramento digital.

Abstract: The starting point of this article is the observation that the COVID-19 pandemic has wide opened the enormous inequalities into Brazilian society and their interrelationships. We understand the Human Rights as historical processes always under construction and in permanent search for fair and decent living conditions for everyone. In this context, we detach the issues related to the right to education. We consider the efforts and struggles of various social groups, particularly since the 1988 Brazilian Constitution, to affirm this right. There have been relevant achievements, but there is still a long way to guarantee quality education to everyone. In the current context of the "emergency remote education" implementation by many municipal and state education systems, we affirm that guarantee everyone's right to communication and information technologies, especially digital media, is strongly needed as a fundamental component of the right to education. However, it is important not to take a merely instrumental view of this issue, often reduced to the use of packages offered by various organizations from a market perspective. It is fundamental considering that the digital culture is increasingly present in different spheres of social life and affects different dimensions of our lives, individually and collectively. It also challenges us, as educators, to understand multiple forms of learning, their possibilities, and limits. The text defends that, beyond the access universalization, it is important to promote digital literacy processes in a continuous, procedural, and systematic way. Both must be oriented to students and teachers to affirm the right to connectivity in a reflexive, critical, and creative educational perspective.

Keywords: Right to education. Right to connectivity. Digital culture. Digital literacy. 


\section{Introdução}

Vivemos em um país e num mundo marcados por contrastes e desigualdades de recursos, oportunidades e direitos, onde cada vez mais uns poucos concentram muitos bens e a grande maioria sofre escassez e exclusão. Não se trata apenas de recursos econômicos, mas de outros aspectos e direitos, como espaço de participação, voz ativa, poder de decisão, informação e oportunidades de aprendizagem.

Certamente, a pandemia escancarou as desigualdades presentes na sociedade brasileira. Reforçou-as e tornou-as evidentes para todos e todas. Muitas têm sido as análises de cientistas sociais sobre o tema. A afirmação da interrelação entre os diferentes âmbitos - econômico, social, da saúde, da educação, etc. - se fez fortemente visível. A pandemia não é democrática, não afeta igualmente a todos os cidadãos e cidadãs. Está especialmente presente entre os grupos sociais mais vulneráveis. Neste contexto de desigualdades plurais e articuladas é que se situam as questões sobre o direito à educação.

A afirmação do direito à educação tem suposto, especialmente a partir da Constituição de 1988, uma luta permanente de educadores e educadoras. Do acesso à permanência na escola. Das condições de trabalho dos educadores à infraestrutura dos estabelecimentos de ensino. Da merenda escolar ao livro didático. Da formação dos/as professores/as às salas de leitura. Do transporte ao material escolar. Muitos têm sido os componentes e dimensões do direito à educação visibilizados e objeto de atenção e reivindicação. A promoção do direito a uma educação de qualidade para todos e todas é uma exigência iniludível na construção da democracia.

No presente artigo focalizaremos de modo especial as novas exigências, principalmente visibilizadas na situação da pandemia, referentes à acessibilidade às tecnologias de informação e comunicação como componente do direito à educação.

\section{Vida digna, direitos humanos e educação}

Conceber a educação como direito humano diz respeito a considerar o ser humano na sua vocação ontológica de querer "ser mais", diferentemente dos outros seres vivos, buscando superar suas condições de existência no mundo. Para tanto, transforma a realidade, convive em sociedade e constrói coletivamente dinâmicas orientadas a aprofundar nas exigências de uma sociedade justa e digna para todos e todas. Ao exercitar estas capacidades, o ser humano faz história, transforma o mundo, agindo nele de uma maneira permanente e ativa. A educação é um elemento fundamental para a realização 
dessa vocação humana, entendida a educação em suas diferentes dimensões, no âmbito formal do sistema escolar e no âmbito não formal. Nesta perspectiva, afirma Andrade (2008):

\begin{abstract}
Na verdade, só somos verdadeiramente humanos se passarmos por um processo educativo. Ninguém nasce pronto e acabado como ser humano. Ao contrário, tornamo-nos humanos por um processo que chamamos de educação e ao qual temos o direito humano básico de vivenciá-lo (p. 55).
\end{abstract}

No atual contexto de pandemia, é importante analisar as condições estruturais e materiais vinculadas à institucionalidade dos direitos humanos, que nesta contingência coloca novos desafios em relação à vigência, interdependência e universalidade dos direitos humanos, como garantias de igualdade e não discriminação para todos e todas.

Nesse sentido, é importante afirmar a centralidade da vida como fundamental, os cuidados, a fragilidade, as necessidades e as mudanças que estão afetando aos alunos e alunas e suas famílias neste momento de crise sociossanitária, articuladamente com o respeito da continuidade do ensinar e aprender e os direitos que permitem que isso seja possível com qualidade educativa.

O direito à educação e a educação em direitos humanos se colocam ainda com mais força no atual momento como um imperativo ético, político e um exercício cotidiano, que requer a formação de um nós coletivo, um grupo social que lute pela efetivação e a construção de uma educação e um sistema educativo emancipador. Isso supõe problematizar a necessidade de transformação da escola, questionar as políticas e as lógicas neoliberais e repensar uma educação que tenha como centro a dignidade humana, a luta pela efetivação de direitos, a democracia e a justiça social. Por isso, os direitos humanos constituem a afirmação da luta dos grupos humanos para ver cumpridos seus desejos e necessidades nos contextos vitais em que estão situados. A luta pela dignidade humana é a razão e a consequência da luta pela democracia e pela justiça.

De acordo com Herrera Flores (2009), a universalidade dos direitos humanos somente pode ser definida tendo como perspectiva.

O fortalecimento de indivíduos, grupos e organizações na hora de construir um marco de ação que permita a todos e a todas criar as condições que garantam de um modo igualitário o acesso aos bens materiais e imateriais que fazem com que a vida seja digna de ser vivida (p. 19).

Tendo presente a centralidade dos direitos humanos é importante reiterar que os direitos não são conquistados de uma vez para sempre, nem são estáticos. Desde o ponto de vista histórico-crítico, os direitos se entendem como processo e como o resultado sempre provisório das lutas que os seres humanos colocam em prática para ter acesso aos bens necessários para a vida e a dignidade humana. 


\begin{abstract}
Entenda-se por dignidade não o simples acesso aos bens, mas que tal acesso seja igualitário e não esteja hierarquizado "a priori" por processos de divisão do fazer que coloquem alguns, na hora de ter acesso aos bens, em posições privilegiadas, e outros em situação de opressão e subordinação. [...] A dignidade é um fim material. Tratase de um objetivo que se concretiza no acesso igualitário e generalizado aos bens que fazem com que a vida seja "digna" de ser vivida (HERRERA FLORES, 2009, p. 31).
\end{abstract}

Hoje, vivemos em sociedades consideradas sociedades do conhecimento. Neste contexto, de acordo com a UNESCO (2020), as sociedades do conhecimento devem ser promovidas e construídas tendo como referência quatro pilares básicos: liberdade de expressão; acesso universal à informação e ao conhecimento; respeito às diversidades cultural e linguística e educação de qualidade para todos.

\title{
Direito à educação para quem?
}

Em 1999, foi criada a Campanha Nacional pelo Direito à Educação³, promovida por um conjunto de organizações da sociedade civil com o objetivo de articular diferentes forças políticas, priorizando ações de mobilização, pressão política e comunicação social, em favor da defesa e promoção do direito à educação. Esta iniciativa pode ser caracterizada como uma rede que congrega um número significativo de grupos e entidades distribuídas por todo o país, incluindo escolas, movimentos sociais, sindicatos, organizações não-governamentais, grupos universitários, juvenis e comunitários, além de cidadãos e cidadãs que acreditam na construção de um país justo, democrático e sustentável por meio da oferta de uma educação pública de qualidade, gratuita, inclusiva e laica.

Os esforços têm sido árduos, certamente conquistas foram alcançadas, mas o atual contexto da pandemia tem tornado evidente que ainda temos muito que caminhar para que a equidade seja efetivamente uma realidade para todas as crianças e jovens, para que possam ter garantido o direito a uma educação de qualidade.

Um aspecto adquiriu especial visibilidade no atual contexto. Tendo presente os inúmeros esforços que têm sido realizados, muitos de maneira improvisada, por redes públicas de ensino e escolas para desenvolver o "ensino remoto emergencial" no período em que as atividades educacionais presenciais foram suspensas em razão da pandemia, as desigualdades de acesso às tecnologias de comunicação e informação, especialmente as mídias digitais ficaram evidentes.

3 Ver: www.campanhaeducação.org.br 
A acessibilidade às plataformas e dispositivos digitais passou a ser encarada como um componente fundamental do direito à educação numa sociedade em que a cultura virtual se faz cada vez mais presente.

Segundo dados disponibilizados pela UNICEF (2020), no início da pandemia no mês de março, no Brasil, 4,8 milhões de crianças e adolescentes de 9 a 17 anos vivem em domicílios sem acesso à internet. A pesquisa mostra, ainda, que, no país, $11 \%$ da população dessa faixa etária não é usuária de internet - não acessando a rede nem em casa e nem em outros lugares nos três meses que antecederam a entrevista. A exclusão é maior entre crianças e adolescentes que vivem em áreas rurais (25\%), nas regiões Norte e Nordeste (21\%) e entre os domicílios das classes D e E (20\%).

Nessas condições de exclusão e vulnerabilidade, a vida digna passa pela procura de efetivação dos direitos que garantam o acesso à conexão de internet, que se torna também um componente do direito à educação.

A Convenção sobre os Direitos da Criança (CDC, 1989) estabelece a obrigação dos Estados de "garantir o acesso da criança a informações e materiais procedentes de diversas fontes nacionais e internacionais, especialmente aqueles que visam à promoção de seu bem-estar social, espiritual e moral e de sua saúde física e mental" (UNICEF, 2020, p. 1).

Com a dimensão continental que tem o Brasil e a diversidade de regiões e condições, além do acesso ao mundo digital, que hoje em dia marca a vida da atual geração de crianças e jovens, é importante neste momento de pandemia também a utilização de outros meios de comunicação adequados para o acesso ao ensino remoto emergencial, como são o rádio e a televisão, que podem ampliar as possibilidades de acesso nos lugares onde a conexão digital não é possível ou muito precária.

Apresentamos alguns dados que reforçam os já mencionados da UNICEF, do estudo realizado pelo IBGE (2018), a partir de dados da Pesquisa Nacional de Amostra de Domicílios (PNAD Continua 2017), sobre a evolução do acesso da população brasileira a diferentes mídias:

- O percentual de domicílios que utilizavam a internet subiu de $74,9 \%$ para 79,1\%, de 2017 para 2018. Nos domicílios rurais, em todas as regiões subiu de 41,0\% em 2017 para 49,2\% em 2018. Na área urbana, a utilização da internet subiu de $80,2 \%$ para $83,8 \%$.

- O rendimento médio per capita dos domicílios em que havia utilização da Internet era quase o dobro do rendimento dos que não utilizavam a rede.

- O equipamento mais usado para acessar a Internet foi o celular, encontrado em $99,2 \%$ dos domicílios com serviço. O segundo foi o microcomputador, que, no entanto, só era usado em $48,1 \%$ desses lares. 
- O rendimento médio per capita dos que utilizavam tablet para navegar na internet era o dobro do recebido por aqueles que acessavam a rede pelo celular e $37,7 \%$ superior ao dos que usavam computador.

- Entre 2017 e 2018, o percentual de pessoas que tinham celular próprio subiu de $78,2 \%$ para $79,3 \%$, chegando a $82,9 \%$ nas áreas urbanas e a $57,3 \%$ nas rurais. - O rendimento real médio per capita dos domicílios em que havia utilização da internet ( $R \$ 1.769)$ foi quase o dobro do rendimento dos que não utilizavam a rede ( $\mathrm{R} \$ 940)$. A grande diferença entre esses dois rendimentos foi observada em todas as regiões do país.

Estes dados evidenciam a expansão da utilização de tecnologias da informação e comunicação no país. No entanto, a brecha entre áreas urbanas e rurais, assim como entre os diferentes grupos socioeconômicos é grande. Não podemos considerar que o aumento do acesso às tecnologias tem favorecido de modo significativo uma maior democratização. Pelo contrário, continua apresentando forte desigualdade, também neste aspecto. Sem uma política sistemática de ampliação do acesso dos grupos socialmente vulneráveis esta brecha tecnológica e digital não será superada.

Esta realidade também está presente nas nossas escolas. Em inúmeros depoimentos de professores e professoras, - em seminários, lives, entrevistas, etc. - neste período de pandemia, são mencionadas as dificuldades de significativo número de alunos e alunas de acessar às tecnologias de informação e comunicação, especialmente as mídias digitais, especialmente dos que vivem nas periferias e pertencem a grupos subalternizados. Além disso, o acesso à internet, quando existe nestas áreas, em geral é de baixa qualidade. Estas realidades também se fazem presentes entre os docentes. As dificuldades de acesso a estes dispositivos têm se revelado um elemento que reforça as desigualdades na efetivação do direito à educação.

Pretto, já em 2008, afirmava:

[...] o desafio está posto: é imprescindível pensarmos em políticas de conexão que incluam, além das necessárias máquinas, o acesso à internet - agora já escrita com o i minúsculo - com velocidade alta, para possibilitar a todos o acesso aos recursos multimídia trazidos pelo intenso movimento de convergência tecnológica e uma apropriação criativa dos meios digitais. Banda larga para todos deveria ser o novo lema, sem dilema (p. 75-76).

É importante termos presente que, nos últimos anos, com a implementação das políticas neoliberais duras e com medidas perversas que só têm concentrado cada vez mais os lucros e aumentado as desigualdades, a educação pública tem se colocado no centro de disputa como um serviço mercantil gerador de lucros e negócios para os grupos empresariais. No momento atual, também as tecnologias são alvo das grandes empresas que for- 
necem plataformas digitais e treinamento para os educadores, assim como das fundações filantrópicas e de diferentes entidades privadas que operam numa lógica mercadológica. No âmbito profissional, através da oferta de pacotes didáticos, comprometem a autonomia da escola e das professoras e professores e implantam uma padronização que nega a diversidade social, cultural e étnica do país e privilegia os mais ricos.

Assumimos uma perspectiva contrária a esta tendência. Não encaramos o direito à conectividade numa perspectiva meramente instrumental. Não se trata simplesmente de dispor da possibilidade de utilizar de alguns dispositivos tecnológicos, por mais importante que isto seja, mas de se ser capaz de entender a cultura digital e trabalhá-la, de modo crítico, reflexivo e criativo, na perspectiva educacional.

Neste sentido, é fundamental levar em consideração que a cultura digital está cada vez mais presente em diferentes âmbitos da vida social. Das operações bancárias à vida doméstica. Da política às relações pessoais. Do mundo do trabalho ao do lazer. Ela afeta nossos modos de aceder e construir conhecimentos, nossas formas de relacionamento, nossas subjetividades, atitudes e comportamentos.

Neste sentido, afirma Almeida (2018):

\begin{abstract}
Na convergência entre espaços presenciais e virtuais surgem novos modos de expressar pensamentos, sentimentos, crenças e desejos, por meio de uma diversidade de tecnologias e linguagens midiáticas empregadas para interagir, criar, estabelecer relações e aprender. Essas mudanças convocam participação e colaboração, requerem uma posição crítica em relação à tecnologia, à informação e ao conhecimento, influenciam a cultura levando à emergência da cultura digital (p. IX).
\end{abstract}

As tecnologias são artefatos culturais potentes e sedutores. A cultura digital nos desafia a entender, como educadores, formas de aprendizagem múltiplas, suas possibilidades e limites. Estamos convidados a penetrar em sua lógica e identificar as potencialidades pedagógicas que podem mobilizar diferentes dinâmicas de ensinar-aprender na perspectiva da construção de novas dinâmicas escolares. Não se trata de demonizar nem exaltar a inserção das tecnologias digitais na escola. Elas são um componente potente da contemporaneidade e devem ser trabalhadas pedagogicamente. Como educadores somos os agentes fundamentais para se avançar na construção de culturas escolares mais inclusivas, criativas e democráticas, assim como para explorar o potencial das tecnologias digitais de informação e comunicação a partir de uma perspectiva reflexiva, crítica e criativa.

Levy (1999), um dos especialistas mais reconhecidos sobre esta temática, perguntado sobre se a cibercultura seria fonte de exclusão, enumera di- 
ferentes possíveis respostas e termina afirmando:

É certo que é preciso favorecer todas as formas adequadas de facilidade e redução dos custos de conexão. Mas o problema do "acesso para todos" não pode ser reduzido às dimensões tecnológicas e financeiras geralmente apresentadas. Não basta estar na frente de uma tela, munido de todas as interfaces amigáveis que se possa pensar, para superar uma situação de inferioridade. É preciso antes de mais nada estar em condições de participar ativamente dos processos de inteligência coletiva que representam o principal interesse do ciberespaço. Os novos instrumentos deveriam servir prioritariamente para valorizar a cultura, as competências, os recursos e os projetos locais, para ajudar as pessoas a participar de coletivos de ajuda mútua, de grupos de aprendizagem cooperativa, etc. [...]

Devem, em contrapartida, evitar o surgimento de novas dependências provocadas pelo consumo de informações ou de serviços de comunicação concebidos e produzidos em uma óptica puramente comercial ou imperial e que têm como efeito, muitas vezes, desqualificar os saberes e as competências tradicionais dos grupos sociais e das regiões desfavorecidas (Levy, 1999, p. 243-244).

\section{Letramento digital um direito a ser reivindicado}

No entanto, para se avançar na perspectiva de afirmar o direito à educação, estamos chamados a promover processos de letramento digital. É comum a afirmação de que, em geral, as crianças e os jovens, navegam com facilidade no mundo virtual. No entanto, sua experiência está marcada pela espontaneidade, pela busca da interatividade, do lazer, utilização de jogos, do domínio de diferentes aplicativos, etc. Uma vivência certamente enriquecedora, mas não desenvolvida de maneira reflexiva e crítica.

No entanto, o letramento digital nos situa em outro patamar de reflexão e formação. Esta expressão - de caráter polissêmico - vem adquirindo cada vez maior reconhecimento e utilização. Para Aquino (2003)

O letramento digital significa o domínio de técnicas e habilidades para acessar, interagir, processar e desenvolver multiplicidade de competências na leitura das mais variadas mídias. Um indivíduo possuidor de letramento digital necessita de habilidade para construir sentidos a partir de textos que mesclam palavras que se conectam a outros textos, por meio de hipertextos, links e hiperlinks; elementos pictóricos e sonoros numa mesma superfície (textos multimodais). Ele precisa também ter capacidade para localizar, filtrar e avaliar criticamente informação disponibilizada eletronicamente e ter familiaridade com as normas que regem a comunicação com outras pessoas através dos sistemas computacionais (p. 1-2).

Certamente, estas são habilidades complexas que devem ser desenvolvidas de forma contínua, processual e sistemática. Neste sentido, exigem um trabalho permanente junto aos educadores e educadoras, crianças e jo- 
vens. O letramento digital possui diferentes dimensões: técnica, cognitiva, interacional, sociopolítica, ética e cultural. Supõe desenvolver processos de reflexão, criticidade e criatividade.

Esta é a perspectiva que assumimos na afirmação da conectividade como um componente do direito à educação na atualidade.

Nesse sentido, é importante destacar o letramento digital com uma visão ampla, como Souza (2007) o entende, tendo presente o contexto sociocultural, histórico e político que envolve o processo entendido como letramento digital.

\begin{abstract}
O letramento digital se constitui como uma complexa série de valores, práticas e habilidades situados social e culturalmente envolvidos em operar linguisticamente dentro de um contexto de ambientes eletrônicos, que incluem leitura, escrita e comunicação (apud FREITAS, 2010, p. 308).
\end{abstract}

Nessa visão, o letramento digital se refere aos contextos social e cultural e de comunicação, bem como aos dispositivos e práticas linguísticos e sociais de comunicação, e os modos pelos quais os ambientes de comunicação têm se tornado partes essenciais de nosso entendimento cultural do que significa ser letrado (FREITAS, 2010, p. 308).

Esse momento de pandemia coloca o desafio de efetivar o direito à educação nas sociedades do conhecimento, o que exige promover amplamente letramento digital, especialmente no processo de formação de professoras e professores, assim como entre os alunos e alunas.

Nesse sentido, é importante repensar os tempos, espaços e recursos que temos e a função que as diferentes TICs poderiam desenvolver, tendo presente a relação com os contextos socioculturais específicos. Esta perspectiva exige desacelerar também na escola, dando tempo e respeitando os processos de ensino-aprendizagem de cada pessoa, assim como ressignificar as estratégicas pedagógicas e as dinâmicas dos processos educativos.

\title{
Para finalizar sem fechar os caminhos
}

A pandemia com o confinamento social acelerou um processo que já estava em curso de introdução mais intensiva das tecnologias de informação e comunicação na educação escolar.

Os meios tecnológicos são importantes, entendidos como ferramentas para o acesso à informação e à produção de certos tipos de conhecimentos. No entanto, é fundamental a promoção de processos de letramento digital. Nesse sentido, o papel do professor/a é fundamental. Somente assim superaremos uma visão meramente instrumental do uso das tecnologias e afirmaremos o direito à conectividade numa perspectiva educacional crítica e criativa. 
Estamos aprendendo juntos, alunos/as e professores/as, a combater o vírus colocando a prova nossas capacidades socioemocionais neste momento de crise da vida em todas suas dimensões, inclusive a planetária. Para lidar com insegurança, desigualdade, ansiedade, medo, isolamento, mudança de rotinas e indefinições é necessário ajudar a desenvolver capacidades tais como, empatia, resiliência, foco, responsabilidade, autonomia, cuidado de si e com o outro.

A implementação do ensino remoto no ensino básico dos sistemas públicos sem os apoios necessários, como já foi evidenciado neste artigo, fere o direito à educação e significa aprofundar as desigualdades socioeducacionais, segregando a maioria dos estudantes. Torna-se urgente promover o acesso às diferentes mídias, assumindo-se o letramento digital numa perspectiva ampla e favorecendo a reflexão e a criticidade.

Em relação ao letramento digital, concordamos com Martín-Barbero (2006) quando afirma:

O lugar da cultura na sociedade muda quando a mediação tecnológica da comunicação deixa de ser meramente instrumental para espessar-se, condensar-se e converter-se em estrutural: a tecnologia remete, hoje, não a alguns aparelhos, mas, sim, a novos modos de percepção e de linguagem, a novas sensibilidades e escritas (p. 54).

Fica o desafio nos novos tempos pós-pandémicos para professores/ as e alunos/as de aprender a aprender, desaprender para reaprender. E, em relação a educação pública, será muito importante se posicionar e afirmar o direito à conectividade das maiorias populares, que reconhecemos como um direito social fundamental, integrante do direito à informação e comunicação, numa perspectiva que promove a autoria, a reflexão crítica e a criatividade.

Este seguirá sendo um desafio quando a pandemia retroceder. Continuará em nossas mãos e corações a luta pela construção de uma educação pública de qualidade para todos e todas, em que o direito à educação em suas diferentes dimensões, incluído o direito à conectividade, seja afirmado numa perspectiva crítica, criativa e democrática. Assim como por uma escola que resiste, ensina e sonha com um novo horizonte social, cultural e educacional de justiça e que promova uma vida digna para todos e todas.

\section{Referências}

ALMEIDA, M. E. B. de Apresentação. In: BACICH, L., MORAN, J. (org.). Metodologias ativas para uma educação inovadora: uma abordagem teórico-prática. Porto Alegre: Penso, 2018. 
ANDRADE, M. É a educação um direito humano? Por quê? In: SACAVINO, S.; CANDAU, V. M. Educação em direitos humanos: temas, questões e propostas. Petrópolis: Dp et Alli, 2008.

AQUINO, R. Usabilidade é a chave para aprendizado em EAD. Disponível em: https://noticias.universia.com.br/destaque/noticia/2005/01/28/490613/usabilidade-e-chave-aprendizado-em-ead.html. Acesso em: 18 jul. 2020

CAMPANHA NACIONAL PELO DIREITO À EDUCAÇÃO. GUIA COVID-19. Educação à Distância. Disponível em: https://media.campanha.org.br/acervo/documentos/COVID-19_Guia3-EaD_FINAL.pdf. Acesso em: 24 jul. 2020

FREITAS, M.T. Letramento digital e formação de professores. Educação em Revista, Belo Horizonte, v. 26, n. 3, p. 335-352, dez., 2010.

HERRERA FLORES, Joaquin. A (re)invenção dos direitos humanos. Florianópolis: Fundação Boiteux, 2009.

LEVY, Pierre. Cibercultura. S. Paulo: Editora 34, 1999.

MARTÍN-BARBERO, J. Tecnicidades, identidades, alteridades: mudanças e opacidades da comunicação no novo século. In: MORAES, D. Sociedade midiatizada. Rio de Janeiro: Mauad X, 2006. p. 51-79.

PRETTO, N.; ASSIS, A. Cultura digital e educação: redes já! In: PRETTO, N.; SILVEIRA, S. A. (org.). Além das redes de colaboração: internet, diversidade cultural e tecnologias do poder [online] Salvador: EDUFBA, 2008.

UNESCO. Transformações e inovações digitais no Brasil. Disponível em: https://pt.unesco.org/fieldoffice/brasilia/expertise/digital-transformation-brazil. Acesso em: 24 jul. 2020.

UNICEF. UNICEF alerta: garantir acesso livre à internet para famílias e crianças vulneráveis é essencial na resposta à Covid-19. Disponível em: https://www.unicef. org/brazil/comunicados-de-imprensa/unicef-alerta-essencial-garantir-acesso-livre-a-internet-para-familias-e-criancas-vulneraveis. Acesso em: 20 jul. 2020. 